\title{
NUMERICAL PREDICTION AND EXPERIMENTAL INVESTIGATION OF CAVITATION EROSION OF HYDRAULIC COMPONENTS USING HFC
}

\author{
Atena Moosavi*, Sven Osterland, Dominik Krahl, Lutz Müller, Jürgen Weber \\ Institut für Mechatronischen Maschinenbau, Technische Universität Dresden, Helmholtzstrasse $7 a, 01069$ Dresden \\ * Corresponding author: Tel.: +49 351 46334109; E-mail address: atena.moosavi@tu-dresden.de
}

\begin{abstract}
Hydraulic devices play an essential role in mechanical engineering due to their high-power density, good controllability, flexible application and high robustness, which expose innovative methods of energy transmission. However, in applications where there is an increased risk of fire or explosion, the commonly used combustible mineral oils represent an unacceptable safety hazard. In such cases, fireresistant, water-based hydraulic fluids are in demand. A special feature of these liquids is their high cavitation tendency and the associated strong erosion wear. The aim of this research is to predict the cavitation behaviour of HFC and the subsequent erosion phenomena using numerical methods and to validate the results with experiments. Additionally, experimental results for HFC were compared with HLP. The findings help to implement further developments to decrease the erosive effect of cavitation in high-pressure differences in hydraulic components. For this purpose, flow geometries of typical hydraulic components, e.g. valve and pump, are used for experimental and numerical investigation. The large-eddy simulation (LES) turbulent modelling is used with Zwart-Gerber cavitation model. The cavitation aggressiveness is quantified by cavitation erosion indices according to Nohmi.
\end{abstract}

Keywords: HFC, Cavitation, Erosion, CFD, Experiment

\section{INTRODUCTION}

Due to their high-power density, good controllability, flexible energy transmission and high robustness, hydraulic drives are of essential importance for machines and systems engineering. However, in applications where there is an increased risk of fire or explosion, the commonly used flammable mineral oils (HLP) represents an unacceptable safety risk. In applications such as mining, foundry and steel rolling mills, but also for power generation or offshore applications, hydraulic fire-resistant fluids should be selected according to the necessary properties to minimize potential risks. Therefore, low-flammable water-based HF fluids have been developed.

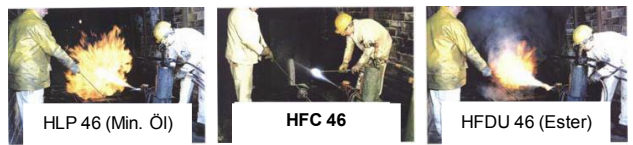

Figure 1: Ignition tendency comparison for HFC and conventional hydraulic oils
One of the most widely used fire-resistant hydraulic fluids, which are nested within the ISO 6743-4:2015 standard is the group of HFC fluids. HFC liquids with a water content between $35 \%$ and $50 \%$ have established themselves as the most common and economical solution, since with the contact of the liquid with a source of ignition, the water evaporates and a spreading of the fire prevents [1] [4]. Figure 1 shows comparison of ignition inclination for HFC, HLP and HFDU.

However, due to the low boiling point of water, the liquid evaporates at a relatively low temperature [3], which significantly changes the fluid property of the remained mixture and impairs the function of the hydraulic components, especially in difficult to access hydraulic systems, e.g. in offshore areas. The high vapour pressure of the water leads to cavitation even at moderate pressure differences in the hydraulic devices. Cavitation reduces efficiency, causes noise and accelerates component wear [6] [17]. Therefore, the use of HFC is severely restricted because of its high cavitation tendency and the consequent erosion damage to the components. The accelerated erosion wear when using HFC 
fluids due to hydrodynamic cavitation phenomenon widely exists in hydraulic machinery such as valves, pumps, turbines and venturi tubes. This results in a limited operating range and potentially costly downtime, which reduces HFC acceptance. This shows that the consideration of cavitation processes is a priority in the development of HFC components.

In this research, a simplified geometry of a hydraulic valve and a control edge of an axial piston pump have been implemented to carry out experiments, and by this way the cavity prone areas characteristics have been identified.

After comprehend experimental survey, the operating points were simulated by ANSYS CFX, using Nohmi cavity related indices to compare numerical results with those of experiment. Then finding a compatible relationship between the intensity of eroded area and Nohmi indices were necessary. Finally, collect data on the causes and effects of cavitation in different operating points are of interest.

\section{FLUID PROPERTIES DETERMINATION}

In order to map the specific fluid properties of HFC in numerical flow simulation and choose the correct cavitation type, it is necessary to parameterize the fluid model based on literature references and experiments. The experimental work focuses on the characteristics of the flow field as a function of fluid temperature. Further investigations are carried out by varying the dissolved air content.

The dimensionless cavitation number $\sigma$ defines the cavitation inclination of liquids. The lower the cavitation number, the more likely the flow is to cavitate, and the greater the number and size of bubbles. As it can be seen in equation (1), $\sigma$ is proportional to the vapour pressure of the liquid and anti-proportional to its density.

$\sigma=\frac{p-p_{d}}{\frac{1}{2} \rho U^{2}}$

Therefore, in further investigations special attention should be paid to the thermodynamic properties and their parameterization in the model.

\subsection{Density}

As part of the parameterization, the dependency of density on temperature and pressure is important. For this Herschel [5] considered two functions $\rho(T)$ and $\rho(p)$. However, the influence of pressure changes on the density for both HLP and HFC is much less than the influence of temperature and $\rho(p)$ is therefore neglected for all subsequent considerations to simplify the modelling.

$\rho(T)=\frac{\rho_{0}}{1+\beta_{T} \cdot\left(T-T_{0}\right)}$

Equation (2) gives the temperature dependency of density, where $\rho_{0}$ is density at ambient pressure at a temperature of $20^{\circ} \mathrm{C}$, and $\beta_{T}$ is the thermal expansion coefficient according to the manufacturer's specifications in the data sheet of the liquid.

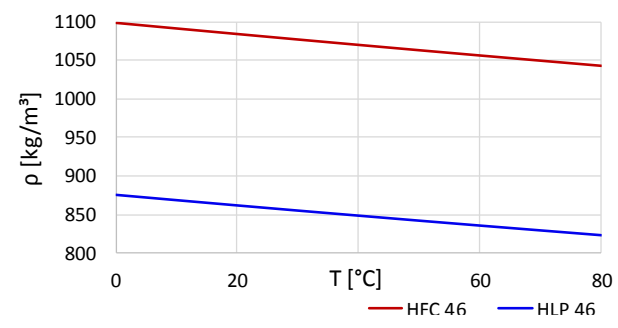

Figure 2: Density-Temperature dependency of HFC and HLP, $\rho_{0, H F C}=1084 \mathrm{Kg} / \mathrm{m}^{3}, \rho_{0, H L P}=$ $862 \mathrm{Kg} / \mathrm{m}^{3}, \quad \beta_{T, H F C}=0.00065 \frac{1}{k}$ $\beta_{T, H L P}=0.00065 \frac{1}{k}$

It can be seen in Figure 2 that HFC has a higher density than HLP. According to equation (1), the cavitation number for HFC is therefore lower than for HLP at the same pressure ratios and volume flows, indicating that HFC is more susceptible to cavitation than conventional mineral oils.

\subsection{Vapour pressure}

In industrial applications, keeping the temperature constant is a normal attempt while operating a hydraulic system. Nonetheless, in narrow spaces such as control notches in valves and pumps, the static pressure can locally fall below a certain level and the hydraulic fluid can cavitate.

The Clausius-Clapeyron relation was implemented, which describes the vapour pressure $p_{D}$ of the liquid at the temperature of $T_{2}$ according to the following equation:

$p_{d 1}=p_{d 1} \cdot e^{C_{d} \cdot\left(\frac{1}{273^{\circ} C+T_{1}}-\frac{1}{273^{\circ} C+T_{2}}\right)}$ 
Where $C_{d}$ is a constant, dependent on the specific latent heat of the liquid and specific gas constant. $p_{D}$ is the vapour pressure at $T_{1}$. The respective values from the data sheets [19] [20] at a temperature of $T_{1}=100{ }^{\circ} \mathrm{C}$ are applied.

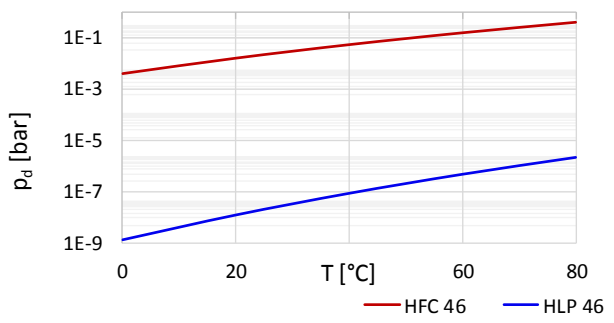

Figure 3: Vapour pressure for HLP and HFC with respect to temperature, According to eq. (2) $p_{d 1, \mathrm{HFC}}=95 \cdot 10^{-3} \mathrm{bar}, \quad p_{d 1 \mathrm{HLP}}=87$. $10^{-9}$ bar, $C_{d, H F C}=5514, C_{d, H L P}=8687$

Vapour pressure is an indicator of the evaporation rate of a liquid. Figure 3 shows the vapour pressure-temperature behaviour for HFC and HLP in comparison. It can be seen that at the same temperature, the vapour pressure of HFC is higher than that of HLP, and consequently waterbased hydraulic fluids evaporate earlier than conventional mineral oils.

\subsection{Viscosity}

The viscosity describes the internal friction in moving liquids. It has a decisive influence on the operating behaviour, in particular on wear and performance losses (internal leakage and pressure losses) [5]. Viscosity is strongly temperaturedependent. This dependency can be determined with the Vogel-Cameron relation, equation (4), according to DIN 53017.

$\eta(T)=A \cdot e^{\frac{B}{T+C}}$

Figure 4 illustrates viscosity of HFC and HLP according to equation (4) with the help of listed coefficients in Table 1.

Table 1: Vogel-Cameron's coefficients for HLP and HFC

\begin{tabular}{lll}
\hline & HLP & HFC \\
\hline $\mathrm{A}[\boldsymbol{P a} \cdot \boldsymbol{s}]$ & $3.9 \cdot 10^{-5}$ & $9.2 \cdot 10^{-5}$ \\
$\mathrm{~B}\left[{ }^{\circ} \boldsymbol{C}\right]$ & 1019 & 1113.4 \\
$\mathrm{C}\left[{ }^{\circ} \boldsymbol{C}\right]$ & 107.5 & 136.7 \\
\hline
\end{tabular}

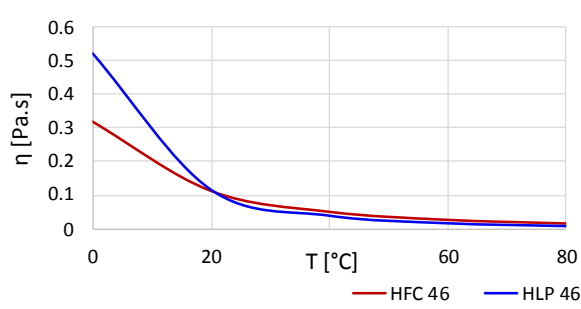

Figure 4: Viscosity-Temperature for HLP and HFC

\subsection{Dissolved air}

An essential part of the parameterization is the analysis of the cavitation behaviour. The amount of gas that can be dissolved in oil is referred to its solubility [16]. In a study of gas evolution in liquids and cavitation, an expression for predicting the volume of dissolved air as a time dependent function was derived [13]. In derived formulation "half-life" term was defined which was experimentally found to be related to solubility constant according to Hennry's law [13] [7]. In literature, a specific search on the air dissolving capacity of HFC, which produces a clear result, does not exist. This makes an experimental determination of this quantity within the study necessary.

Bunsen coefficient indicates how much volume of a gas $V_{G}$ is absorbed in the volume of another substance $V_{L}$ at a partial pressure corresponding to the standard pressure in the physical standard state. A specific test bench, the hydraulic tensile test, which generates a defined pressure drop via volume expansion within a closed cylinder, is used [12]. The Bunsen coefficient of HFC and HLP could be measured using the trend line in the volume ratio-pressure diagram from different operating points, Figure 5.

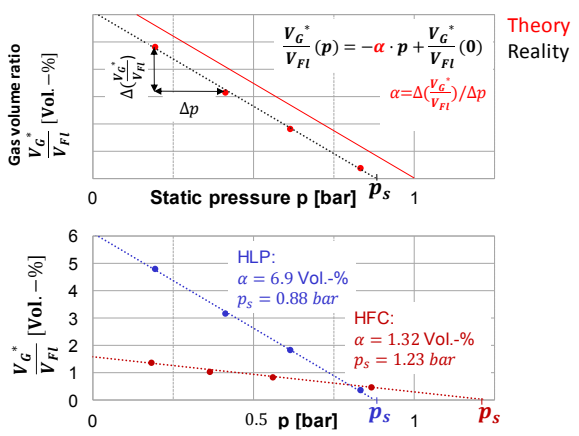

Figure 5: Experimental investigation of the air dissolving capacity for HFC and HLP 
Experimental investigations on Bunsen coefficient of HLP and HFC show that the gas solubility of HLP is $6.9 \%$ vol.\%, while HFC can dissolve up to $1.32 \%$ vol. $\%$ of free air, which is 5.2 times less than HLP. According to Totten [16] water can dissolve $1.8 \%$ vol. $\%$ of free air. Meanwhile, water vapour pressure changes strongly with increasing temperature. This illustrates the vapour cavitation sensitivity of water compared to mineral oil. In previous studies, gas cavitation is often neglected for water due to the dominant vapour cavitation [2] [14]. Since HFC is a water-based liquid and the product used in experimental part of this study contains $45 \%$ water [19], its cavitation behaviour is approximately equal to that of water. In this research work, gas cavitation of HFC is negligible and only vapour cavitation is considered as the dominant cavitation type. In reverse, HLP has a significant greater capacity of dissolving air, so that gas cavitation cannot be neglected for HLP.

\section{EXPERIMENTAL SETUP PROCEDURE}

An experimental investigation was undertaken to study cavitation damage in a simplified, flat diaphragm geometry of spool valve and axial piston pump, as they are most relevant devices to control hydraulic systems. Figure 6 illustrates scheme of these experimental geometries.
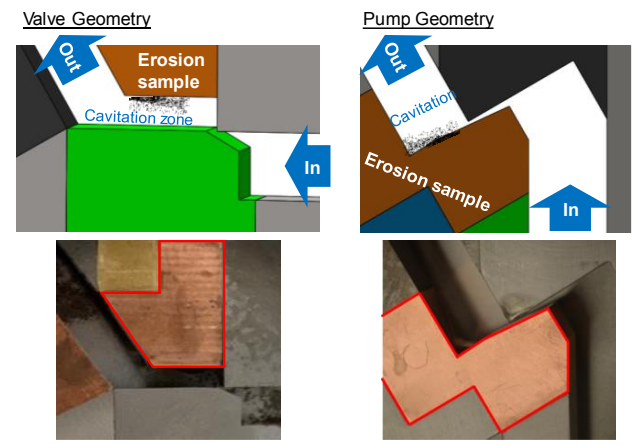

Figure 6: Simplified flat diaphragm geometry of spool valve and axial piston pump

The test facility designed by Mueller [10] was implemented in experimental attempts. It can deliver the required pressure difference, temperature and volume flow rate for the measurement of cavitation erosion. For continuous data recording, temperature and pressure sensors have been mounted at both inlet and outlet of the test geometry. Additionally, a high-speed camera, including lighting and optical components, as in Figure 7, have been implemented to record fluid dynamic process with shadowgraphy [15]. Shadowgraph is a density sensitive technique, based on a back illumination and an appropriate defocusing [8]. This method as an optical diagnostic technique is sensitive to density gradients in fluid flow [9].

The experimental analysis of cavitation wear on the valve and pump model was done with both HLP 46 and HFC 46 hydraulic fluids. The exchangeable copper samples, exposed to the erosion area, were tested at different operating points for both HLP and HFC. Each operating point was recorded and analyzed in an ongoing test with a measurement time of 5 hours each.

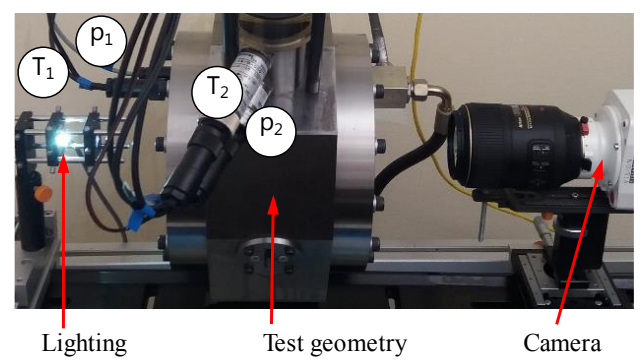

Figure 7: Visual recording of experiment by highspeed camera
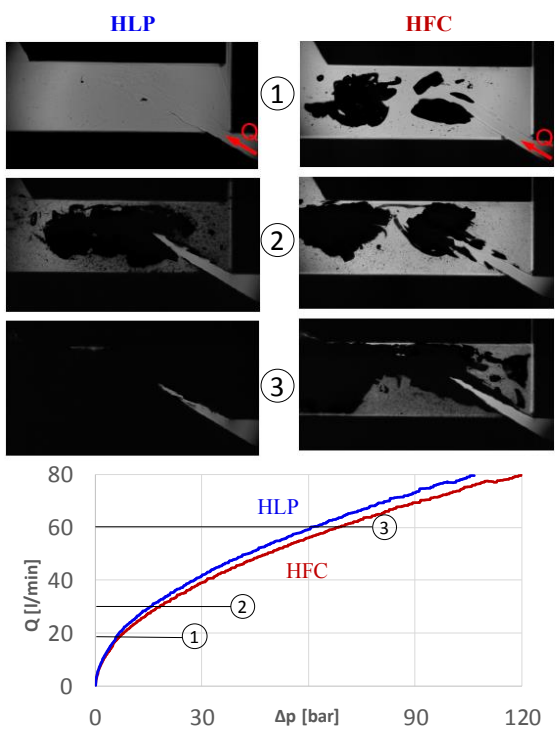

Figure 8: Cavitation intensity comparison for $\mathrm{HFC}$ and HLP at $25^{\circ} \mathrm{C}$ for valve 
Figure 8 shows high-speed images, which captured the intensity of cavitation with shadowgraphy method at constant temperature of $25^{\circ} \mathrm{C}$ but several pressure differences, for both hydraulic fluids HLP and HFC. In HFC, cavitation already starts at lower pressure differences or volume flows than in HLP due to the different saturation vapour pressures, state (1). As the volume flow increases, the proportion of cavity bubbles increases in both, HLP and HFC. As the volume flow increases, the proportion of gas-filled cavities increases in both, but more strongly for HLP than for HFC. This is caused by the release of larger amounts of dissolved air in HLP, while the amount of free air can be assumed to be zero in HFC according to section 2.4.

Before and after each erosion test, the surface of the erosion sample was photographed then it was scanned and analyzed using a 3D profilometer, Figure 9. The available 3D surface topography was used to determine both the depth of erosion and the volume removal of the entire sample compared to the non-eroded initial state.

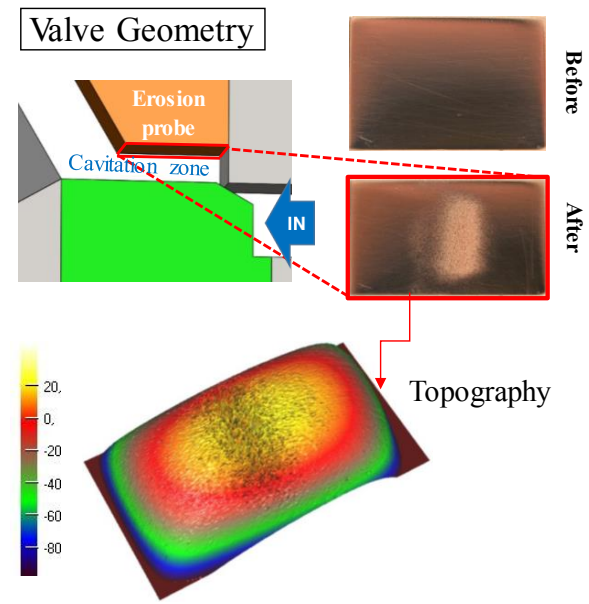

Figure 9: Comparison of erosion probe, before and after test and 3D surface topography after completed erosion test with HFC for Valve

The data in Table 2 gives an overview of the volume removal determined for HLP and HFC at two operating points.

Figure 10 clearly shows that under comparable flow conditions, cavitation at HFC 46 is considerably more aggressive than at HLP 46 and thus leads to significantly greater material removal. The higher the temperature and pressure difference, the higher the removal of material by cavitation erosion.

Table 2: Comparison of the erosion material removal for HFC and HLP in a selected operating point at $\boldsymbol{T}=60^{\circ} \mathrm{C}$

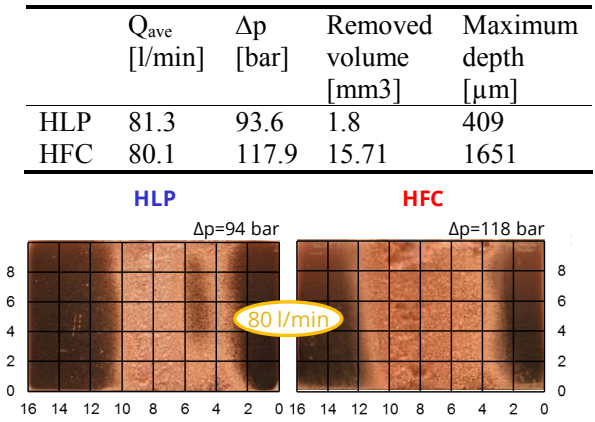

Figure 10: Comparison of the erosion intensity for HFC and HLP at constant volume flow rate of $80 \mathrm{l} / \mathrm{min}$ at $T=60^{\circ} \mathrm{C}$ for valve

\section{NUMERICAL METHOD}

The aim of the numerical investigation is to identify the zones which are at risk of cavitation and to predict the intensity of erosion using simulation-based methods. In the first step towards numerical flow simulation and analysis, the exact dimensions of the test geometries, used in the test stand, were carefully measured so that the models could be created and meshed in Ansys ICEM. The substantial fluid zones e.g. flow entrance and areas near to the walls, were finely and carefully meshed by blocking method due to the importance effect of the erosion in these parts. The mesh network of valve and pump geometries have 1601280 and 1989844 hexahedral elements, respectively. Boundary zone type specifications, such as WALL, INLET or OUTLET, defined the characteristics of the model at its external or internal boundaries. Consequently, the geometry was imported to Ansys CFX for further calculation.

\subsection{Turbulent model}

Vapour cavitation refers to the process by which vapour forms in a low-pressure region of a liquid flow. Here a turbulent model that can reproduce low-pressure regions in the flow spatially and temporally, and corresponds almost exactly to the experiment is essential. Initially, independent of the cavitation model, SST and LES turbulent 
models were examined to see which approach can depict the necessary pressure drop at the selected operating points from experiments. As the simulations were conducted with cavitation free turbulent modelling, the data from experiment were also compared in the cavitation free area. According to Figure 11, both SST and LES show a good consistency for pressure drop with experimental results.

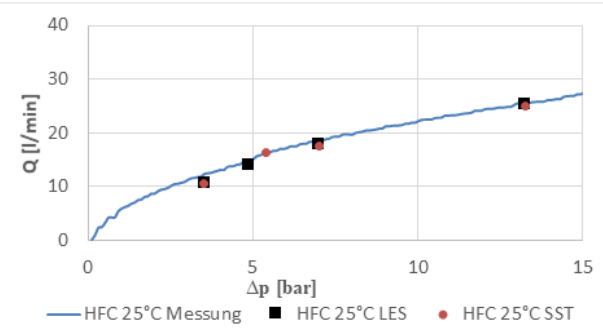

Figure 11: Simulation and experiment comparison of Q- $\Delta \mathrm{p}$ in Cavitation free area
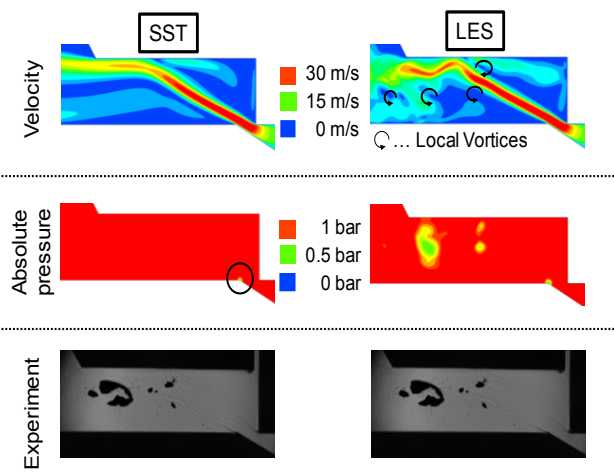

Figure 12: Comparison of Velocity and Pressure simulated by SST and LES models with visual high-speed photos for Valve

Figure 12 shows a glance of velocity field simulated by SST and LES model approaches, as well as a comparison of the absolute pressure in both models with an experimentally recorded cavitation high-speed image. The result shows that the modeling of large-scale vortices is a prerequisite for a correct mapping of the cavitation-relevant pressure drops where RANS modeling, like the SST model e.g. is not able to predict that. RANS models cannot calculate potential cavitation areas in the form of low local pressures at the points, where they occur in the experiment, although the flow characteristics are well reproduced by SST.

\subsection{Cavitation model}

In CFX, cavitation models are implemented in the multiphase framework as an interphase mass transfer model to simulate the growth of bubbles in a liquid, which user-defined coefficient quantities can be used. In this research HFC and ideal gas water vapour were considered the participant phases. As the vapour volume fraction increases, the nucleation site density must decrease accordingly. With this mind, here the Zwart-Gerber-Belmari [18] cavitation model parametrized for water which is compatible for vaporization with all the turbulence models available in ANSYS, was used as cavitation model for the HFC. Assuming that all the bubbles in a system have the same size, Zwart-GerberBelamri proposed that the total interphase mass transfer rate per unit volume $(R)$ is calculated using the bubble radius $\left(R_{b}\right)$, nucleation site volume fraction $\left(\alpha_{n u c}\right)$ and evaporation coefficient $\left(F_{\text {evp }}\right)$, Equation (5).

$R=F_{\text {evp } / \text { cond }} \cdot \frac{3 \alpha_{n u c} \rho_{d}}{R_{b}} \cdot\left(\sqrt{\frac{2}{3} \cdot \frac{\left|p_{d}-p\right|}{\rho_{l}}}\right)$

Where bubble radius is $R_{b}=10^{-3} \mathrm{~mm}$, nucleation site volume fraction is $\alpha_{n u c}=5$. $10^{-4}$, evaporation coefficient is $F_{\text {evp }}=50$ and condensation coefficient is $F_{\text {cond }}=0.001$.

\subsection{Cavitation index}

Nohmi [11] introduced four different indices with which the aggressiveness of vapour cavitation on solid surfaces can be numerically calculated as a function of the local vapour volume fraction and pressure. Nohmi indices are given in equation (6), (7), (8) and (9).

$$
\begin{aligned}
& \text { Noh } 1=\int_{0}^{T_{s i m}} \alpha_{d} \cdot \max \left(\frac{\delta p}{\delta t}, 0\right) d t \\
& \text { Noh2 }=\int_{0}^{T_{s i m}} \alpha_{d} \cdot \max \left[\left(p-p_{d}\right), 0\right] d t \\
& \text { Noh } 3=\int_{0}^{T_{s i m}} \max \left[\left(p-p_{d}\right), 0\right] \cdot \\
& \max \left[-\frac{\delta \alpha_{d}}{\delta t}, 0\right] d t \\
& \text { Noh } 4=\int_{0}^{T_{\text {sim }}} \max \left[-\frac{\delta \alpha_{d}}{\delta t}, 0\right] d t
\end{aligned}
$$

To select the best index with the most accurate prediction of erosion, the numerical data for the four Nohmi indices and the experimental results were compared in two operating points with low and high intensity of cavitation erosion. Numerical investigation shows that Nohmi3, 
given by equation (8), is more compatible with experimental results and calculates cavitation erosion more accurate than the other Nohmi indices. Figure 13 shows a good consistency between experiment and simulation using Nohmi3. For both operating points, both the local prediction of erosion and its intensity agree well with the experimental damage on the erosion samples.

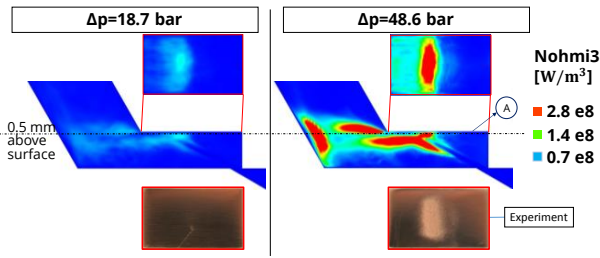

Figure 13: Comparison of Nohmi3 erosion prediction with experimental results of Valve at low and high cavitation intensity

Finally, all simulations were carried out isothermally with LES turbulent model, using Zwart-Gerber-Blamari as cavitation model for the flow at the selected operating points. Nohmi3 was used as the most reliable prediction index of cavitation areas and used for all further simulations.

\section{RESULTS AND DISCUSSION}

After conducting experimental and numerical investigations, results were compared. Table 3 shows valve's operating points from experiments which were simulated in Ansys CFX.

Table 3 Valve geometry experimental operating points

\begin{tabular}{lllll}
\hline VOP & $\begin{array}{l}\text { T } \\
{\left[{ }^{0} \mathrm{C}\right]}\end{array}$ & $\begin{array}{l}\mathrm{p}_{1} \\
{[\mathrm{bar}]}\end{array}$ & $\begin{array}{l}\mathrm{p}_{2} \\
{[\mathrm{bar}]}\end{array}$ & $\begin{array}{l}\mathrm{Q}_{\text {ave }} \\
{[1 / \mathrm{min}]}\end{array}$ \\
\hline 1 & 25 & 10.5 & 1.24 & 21.8 \\
2 & 25 & 15 & 1.0 & 26.5 \\
3 & 25 & 20 & 1.3 & 31 \\
4 & 25 & 50 & 1.4 & 51 \\
5 & 40 & 50 & 1.4 & 54 \\
6 & 40 & 123 & 1.55 & 80 \\
7 & 60 & 50 & 1.4 & 51.5 \\
8 & 60 & 119 & 0.99 & 80 \\
\hline
\end{tabular}

At operating point VOP1, water vapour bubbles started to appear and occupied approx. 20 $\%$ of the flow space. According to Bernoulli if the static pressure falls locally below the saturation vapour pressure, cavitation begins. In order to cover the entire operating range, in accordance with the experimental investigations, the pressure difference between inlet and outlet was gradually increased with regard to the cavitation tendency. It was found that with rising temperature and rising pressure drop/volume flow rate, the cavitation tendency in the flow increases. This is shown by the simulation results based on experimental operating points and the surface analysis of the experimental erosion samples from 3D scanner. Figure 14 and Figure 15 show examples of this correlation for low and high intensity of erosion, VOP3 and VOP4, at $25^{\circ} \mathrm{C}$. Pressure difference between inlet and outlet (consequently also the volume flow) at constant fluid temperature was increased from 18.7 bar at VOP3 to 48.6 bar at VOP4. It can be seen that by increasing the pressure difference, Nohmi3 index increased and more erosion was predicted in the operating point with higher pressure drop.

The erosion prediction in higher pressure difference is also interesting. For VOP6, Figure 16 and for VOP8, Figure 17 show a comparison between simulation and experiment results. Numerically predicted cavitation erosion through Nohmi3 index was compared with the 3D surface scan of the experiment erosion sample. In VOP6 a maximum water vapour content of $88.7 \%$ and in VOP8 $85.4 \%$ was determined numerically.

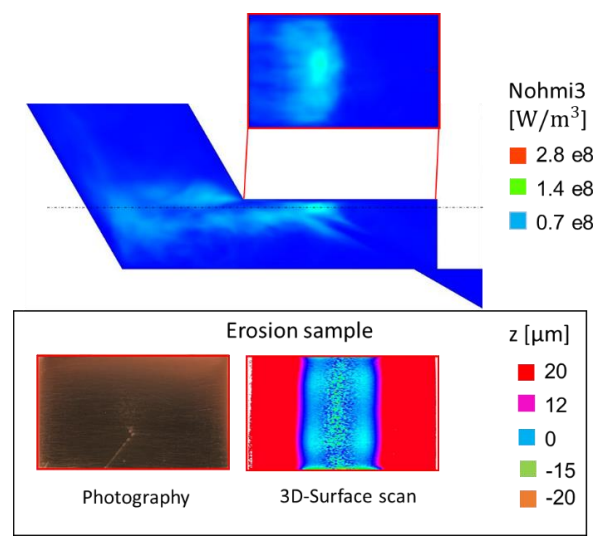

Figure 14: Comparison between simulated cavitation aggressiveness determined using Nohmi3 and experimental 3D surface scan of erosion sample for VOP3 in valve 


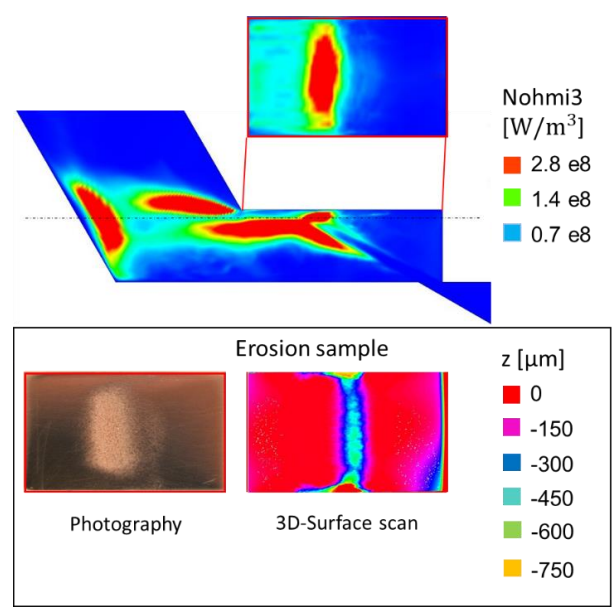

Figure 15: Comparison between simulated cavitation aggressiveness determined using Nohmi3 and experimental 3D surface scan of erosion sample for VOP4 in valve

After comparing the simulation results with the experimental results, obtained from 3D surface scan of the erosion samples, it was determined that the Nohmi3 index can reliably predict the degree of cavitation aggressiveness in the valve geometry. The investigations over valve geometry have shown that with increasing pressure difference and fluid temperature the effects of erosion become more intense, which is also predictable in the numerical simulation model.

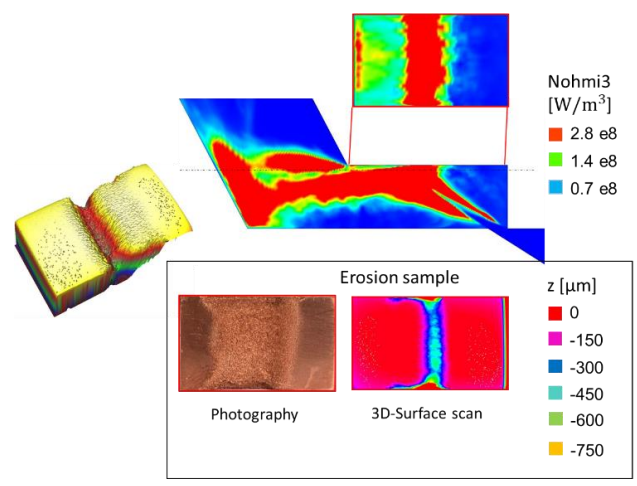

Figure 16: Comparison between simulated cavitation aggressiveness determined using Nohmi3 and experimental 3D surface scan of erosion sample for VOP6 in valve

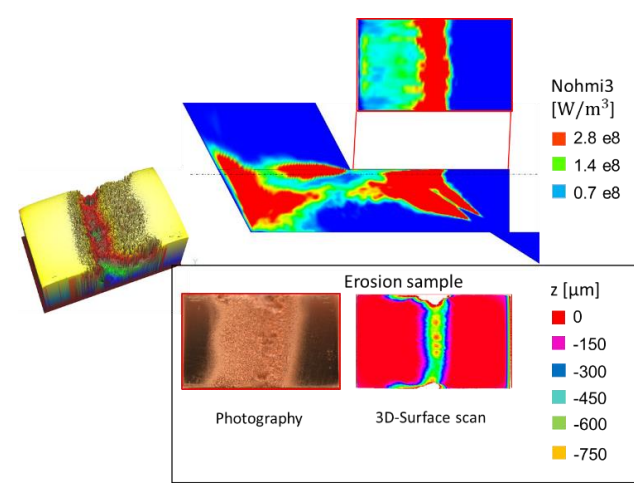

Figure 17: Comparison between simulated cavitation aggressiveness determined using Nohmi3 and experimental 3D surface scan of erosion sample for VOP8 in valve

Table 4: Pump geometry experimental operating points

\begin{tabular}{lllll}
\hline POP & $\begin{array}{l}\mathrm{T} \\
{\left[{ }^{0} \mathrm{C}\right]}\end{array}$ & $\begin{array}{l}\mathrm{p}_{1} \\
{[\mathrm{bar}]}\end{array}$ & $\begin{array}{l}\mathrm{p}_{2} \\
{[\mathrm{bar}]}\end{array}$ & $\begin{array}{l}\mathrm{Q}_{\mathrm{ave}} \\
{[1 / \mathrm{min}]}\end{array}$ \\
\hline 1 & 40 & 20.1 & 2.3 & 17.4 \\
2 & 40 & 25 & 2.2 & 20.2 \\
3 & 40 & 30 & 1.3 & 22.4 \\
4 & 40 & 99 & 1.9 & 42 \\
5 & 40 & 150.5 & 1.26 & 51 \\
\hline
\end{tabular}

For further investigation, the numerical methods were developed to determine cavitation intensity and erosion wear for another typical hydraulic component. Here the same numerical procedure was taken for the control edge of an axial piston pump, which were under investigation experimentally. Table 4 gives the experimental operating points for the pump geometry that were simulated numerically in the same way as the valve geometry.

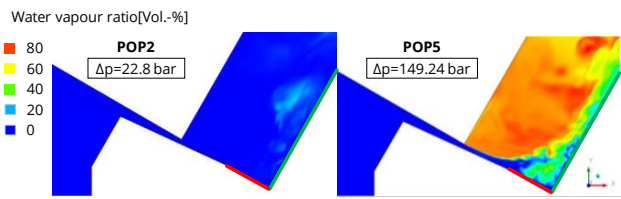

Figure 18: Water vapour ratio comparison in low and high intensity of cavitation for pump geometry at $T=40^{\circ} \mathrm{C}$

HFC flow was simulated in CFX with POP1 condition through pump geometry, as the starting point of the numerical simulation. At this point there is no erosion and the produced water 
vapour, is negligible. By increasing the pressure difference between inlet and outlet, the vapour bubbles started to shown up in the fluid flow, Figure 18.

Nohmi3 index was evaluated not only on midplane but also on the sidewalls where the erosion damage might be expected. The results from two most intensive erosion at $40^{\circ} \mathrm{C}$ on the pump geometry are shown in Figure 19 and Figure 20.

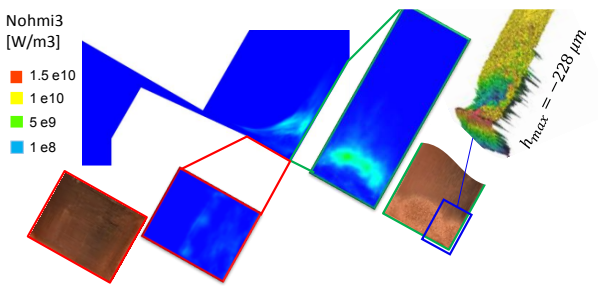

Figure 19: Comparison between simulated cavitation aggressiveness determined using Nohmi3 and experimental 3D surface scan of erosion sample for POP4 in pump

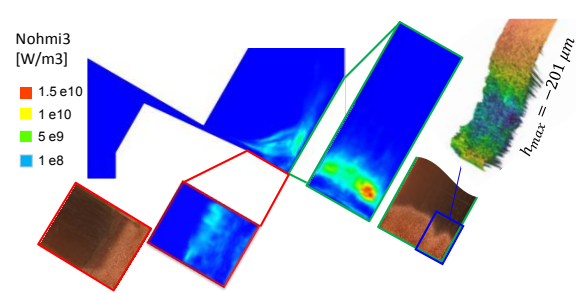

Figure 20: Comparison between simulated cavitation aggressiveness determined using Nohmi3 and experimental 3D surface scan of erosion sample for POP5 in pump

Figure 19 and Figure 20 indicate that Nohmi3 can predict the erosion also over pump geometry correctly in the terms of spatial and temporal and it can be developed for erosion prediction of other hydraulic geometries.

\section{CONCLUSION AND OUTLOOK}

Fire-resistant HF fluids, mainly HFC fluids, are legally required in branches of industry with ignition risk. However due to the low boiling point of water, the operating range of HFC components is severely limited compared to conventional mineral oil. The cavitation phenomena when using HFC fluids and the associated cavitation erosion when the permissible operating limits are exceeded are particularly critical. For an economic development of HFC components, however, a systematic processing of the HFC-specific cavitation properties as well as an efficient possibility as a simulation-based prediction of cavitation erosion is missing.

In order to enable a simulation-supported mapping of the flow processes, the material value of the cavitation-relevant fluid parameters was first determined. The experimental investigations showed a significantly lower air dissolving capacity of HFC compared to conventional mineral oil, HLP.

In the further course of the work, the cavitation behaviour was analysed on a typical valve geometry and on the control edge of an axial piston pump experimentally to validate the fluid and cavitation model numerically. All experiments were carried out with HFC and HLP for comparison purposes. The subsequent study on the suitability and validation of different simulation model approaches showed that for the correct mapping of the cavitation-relevant pressure drop the calculation of the large-scale vortices by means of LES simulation is necessary.

With the experimental cavitation erosion analysis, a simulation-based erosion model was developed and comprehensively validated. Corresponding erosion tests were completed with HLP and HFC on two typical hydraulic geometries. Additionally, the damage area and the volume removal of the respective erosion samples were scanned with a 3D profilometer.

The results of the numerical prediction of the cavitation erosion showed that the cavitation index Nohmi3 could predict the damage intensity and its spatial distribution well for both geometries. Based on numerical and experimental analysis on the valve and pump geometry, it was found that, the degree of local erosion risk over the solid surface could be well predicted qualitatively with the cavitation index Nohmi3.

The documentation of the methods and used tools, with results obtained from this research should enable manufacturers to apply them to their own products in order to make their hydraulic equipment more efficient and robust. 


\section{NOMENCLATURE}

\begin{tabular}{|c|c|c|}
\hline$\alpha_{n u c}$ & - & Nucleation site volume fraction \\
\hline$F_{\text {cond }}$ & - & Condensation coefficient \\
\hline$F_{e v p}$ & - & Evaporation coefficient \\
\hline $\mathrm{h}$ & $\mu m$ & Depth \\
\hline $\mathrm{m}$ & $\mathrm{kg}$ & Mass \\
\hline $\mathrm{p}$ & bar & Pressure \\
\hline Q & & Volume flow rate \\
\hline $\mathrm{R}$ & $\frac{\operatorname{mg}}{\mathrm{s} \cdot \mathrm{m}^{3}}$ & $\begin{array}{l}\text { Total interphase mass transfer rate per } \\
\text { unit volume }\end{array}$ \\
\hline $\mathrm{R}_{\mathrm{b}}$ & $\mathrm{mm}$ & Bubble radius \\
\hline $\mathrm{R}_{\mathrm{g}}$ & $\frac{J}{k g \cdot K}$ & Specific gas constant \\
\hline $\mathrm{t}$ & $S$ & Time \\
\hline $\mathrm{U}$ & & Velocity \\
\hline$\eta$ & $\frac{\mathrm{kg} \cdot \mathrm{m}}{\mathrm{s}}$ & Dynamic Viscosity \\
\hline$\varrho$ & $\mathrm{Kg} / \mathrm{m} 3$ & Density \\
\hline$T$ & ${ }^{\circ} \mathrm{C}$ & Temperature \\
\hline
\end{tabular}

\section{REFERENCES}

[1] Bock W (2009) Hydraulic Fluids - a Liquid Machine Element. VFMZ, Mainz, 2009

[2] Bakir F., Rey R. (2004) Numerical and Experimental Investigations of the Cavitating Behavior of an Inducer. Int. J. Rotating Mach., 10(1), pp. 15-25, 2004

[3] Bosch Rexroth (2015) Schwerentflammbare Hydraulikflüssigkeiten-wasserhaltig,

Anwendungshinweise und Anwendungsanforderungen. RD 90223, 2015

[4] Fuchs Petrolub (2002) Im Brennpunkt: Optimaler Brandschutz mit schwer entflammbaren Hydraulikflüssigkeiten. FuchsInfo, Mai 2002

[5] Herschel D (2014) Druckflüssigkeiten für Hydraulikanlagen. Springer, 2014

[6] Hodges P (1996) Hydraulic Fluids, Elservier Ltd., Oxford, 1996
[7] Kim S, Murrenhoff H (2012) Measurement of Effective Bulk Modulus for Hydraulic Oil at Low Pressure. Journal of Fluids Engineering, 134 (2):021201, 2012

[8] Mauger C (2012) Shadowgraph, Schlieren and interferometry in a 2D cavitating channel flow. pringer-Verlag, 2012

[9] Merzkirch W (1981) Density sensitive flow visualization, in: Fluid Dynamics, Ed. R. J. Emrich, Methods of Experimental Physics, Vol. 18, Academic Press, New York, 1981

[10] Mueller L (2013) Messverfahren und numerische Modellierung von Kavitation in einem ölhydraulischen Ventil. O+P 2, 2013

[11] Nohmi M, Ikohagi T, Iga Y (2008) Numerical Prediction Method of Cavitation Erosion. Proceedings of FEDSM, 2008

[12] Petzold M (2016) Dosiergenauigkeit, Wirkungsgrad und Geräusch von elektromagnetisch angetriebenen Kolbenpumpen, Dissertation, TU Dresden, 2016

[13] Schweitzer P. H., Szebehely V.G. (1950) Gas Evolution in Liquids and Cavitation. Journal of Applied Physics, Vol.21, pp. 1218-1224, 1950

[14] Seo J. H. (2008) Prediction of Cavitating Flow Noise by Direct Numerical Simulation. J. Comput. Phys., 227(13), pp. 6511-6531, 2008

[15] Settles G (2001) Schlieren and Shadowgraph Techniques. Springer-Verlag, ISBN 3-54066155-7, 2001

[16] Totten G. (2000) Handbook of Hydraulic Fluid Technology. United States of America, Marcel Dekker, 2000

[17] Totten G, Wills D, Feldmann D (2001) Hydraulic Failure Analysis - Fluids, Components, and System Effects. ASTM special technical publ. 1339, 2001

[18] Zwart P, Gerber A, Belamri T (2004) A TwoPhase Flow Model for Predicting Cavitation Dynamics. ICMF 2004 International Conference on Multiphase Flow. Yokohama, Japan, 2004

[19] Fuchs data sheet (2014) Hydrotherm 46 M type HFC data sheet. Fuchs, 130, 2014

[20] Elaskon data sheet (2017) HLPD 46, mineral oil. Elaskon, 2017 